\title{
ELECTROCARDIOGRAPHIC P WAVE AND ATRIAL WEIGHTS AND VOLUMES
}

\author{
BY \\ RICHARD GORDON, GRAEME NEILSON, AND HAROLD SILVERSTONE \\ From the Princess Alexandra Hospital, Brisbane, and the Departments of Medicine and of Social and Preventive Medicine, \\ University of Queensland, Australia
}

Received January 28, 1965

It has been well recognized that certain disease states such as rheumatic valvular heart disease are associated with alterations in the size of the atria. In this same group of patients characteristic abnormalities in the electrocardiographic $P$ wave are often present, and have come to be accepted as strong evidence for abnormal atrial size-usually referred to as either "hypertrophy" or "dilatation" depending on the configuration of the P wave (Macruz, Perloff, and Case, 1958; Soloff and Zatuchni, 1958; Dines and Parkin, 1959).

Whether these characteristic $P$ wave changes are invariably associated with atrial abnormalities, or how close the relationship is, could be determined only by comparing the electrocardiograms and atria of individual patients. Though the hearts of such patients have been examined at necropsy (Berliner and Master, 1938), exact measurements of atrial weights and volumes have not been made.

A second approach to the recognition of abnormalities of the atria has been to employ exact measurement of the height and duration of the $P$ wave, usually in a specified lead (Katz, 1946; Caceres and Kelser, 1959). Reference is then made to one of the "normal ranges" for the electrocardiographic $\mathbf{P}$ wave, derived from the tracings of apparently normal young subjects (Ashman and Hull, 1941; Leatham, 1950; White, 1951; Caceres and Kelser, 1959). Since these hearts are not available for examination except perhaps in a department of forensic medicine dealing with accident victims, detailed relationships between atrial parameters and $P$ wave measurements have not been expored in this group either.

There is, however, material available for such comparison: patients who have had an electrocardiogram performed during life and later have come to necropsy. Such a group was studied in an attempt to derive the factors, atrial and other, responsible for the configuration of the $P$ wave, and to determine how closely the $\mathbf{P}$ wave in an individual case is related to atrial size.

\section{SuBJeCTS AND MeTHODS}

Ninety-eight patients who were submitted to routine necropsy in the Princess Alexandra Hospital were the subjects of this study. At least one electrocardiogram had been taken in each.

(1) Atrial Volumes. A thin rubber condom measuring $20 \mathrm{~cm}$. in length and $11 \mathrm{~cm}$. in circumference was used to measure atrial volumes. A length of stout cotton was tied to the extremity of the closed end of the condom and threaded through the eye of a round-bodied needle and tied. The heart was removed with lengths of 2 to $4 \mathrm{~cm}$. of aorta, pulmonary artery, venæ cavæ, and pulmonary veins attached, and washed with water until all chambers were free of clots. The needle was introduced through the inferior vena caval opening in the case of the right atrium, and through the right inferior pulmonary vein opening in the case of the left atrium, and the point passed through the tip of the respective atrial appendage. The cotton was drawn through until the "teat" of the condom was resting in the atrial appendage. Water was then introduced at about $1 \mathrm{ml} . / \mathrm{sec}$. until the atrium was fully distended at a pressure of $3 \mathrm{~cm}$. of water. The open 
end of the condom was then pinched off and it was removed, its contents being measured in a graduated glass cylinder. If the condom herniated through one of the other atrial openings, pressure was released and filling recommenced.

The degree of rigor mortis of the heart, judged by appearance and pliability of the chamber walls, and of the jaw, arms, and legs, judged by their resistance to movement, was assessed on a five-point scale.

(2) Atrial Weights. The aorta was cut off just above the valve ring (to leave the coronary ostia intact), the pulmonary artery at the valve ring, and the great veins at their point of entry into the atria. Any adherent tissue such as parietal pericardium was removed, but no attempt was made to dissect off the epicardial fat. The amount of epicardial fat was assessed on a five-point scale. The coronary arteries were opened along their length using fine-pointed scissors, as in the normal dissection of the heart. Total heart weight was then measured.

With the left index finger introduced into the left atrium through a pulmonary vein opening, and the left thumb into the right atrium through a caval opening, the interatrial septum was grasped between these digits hard up against its anterior end. Using a metal probe dipped in Bonney's Blue dye, and moving the digits backwards along the septum at its junction with the atria, the position of interatrial septum was marked on the outer surface of the heart. This line helped greatly in dissection of the atria from the septum.

Using scissors, each atrium was dissected off the atrio-ventricular groove as far as the septum, and the dissection was continued along the line previously drawn. The septum was then dissected off, using the atrioventricular groove as a guide, leaving the mitral and tricuspid valve leaflets attached to the ventricles.

The two atria were weighed separately, and then together, with the septum, as the combined atrial weight. Two blocks, $1 \mathrm{~cm}$. in length and $4 \mathrm{~mm}$. in width, were cut from each atrium, one from the atrial appendage, and one from a part of the atrial wall free from musculi pectinati. Sections from these blocks were examined microscopically for adipose tissue and this was assessed on a five-point scale.

(3) Other Details Recorded at Necropsy. Age at death, sex, and the thickness of the subcutaneous fat (measured at a point $2 \mathrm{~cm}$. below the umbilicus along the midline incision) were recorded.

(4) Electrocardiographic Measurements. In those cases where several electrocardiograms were available, the most recent one was chosen for study. A hand lens was used and measurements were made to a quarter of a millimetre on standard electrocardiographic paper. For reasons discussed below the height and duration of the $\mathbf{P}$ wave and the $\mathbf{P}-\mathbf{R}$ interval were measured in the particular lead (or leads) in which these values were greatest. In each case the mean of measurements in three complexes was recorded.

\section{RESULTS}

The average age of the series was 69 years.

Since nearly all the patients were elderly, most of them were found at necropsy to be suffering from several pathological processes. The primary cause of death is shown in Table I.

Apart from the 9 per cent of patients whose primary cause of death was hypertension, a further 17 per cent had diastolic blood pressures persistently greater than $100 \mathrm{~mm}$. $\mathrm{Hg}$ and were regarded clinically as being hypertensive. Similarly, in addition to the 31 per cent of patients dying from coronary artery disease, a further 27 per cent had coronary atheroma of at least moderate severity associated with myocardial fibrosis. When the effects of prolonged sepsis and of anæmia associated

TABLE I

Primary Cause of Death

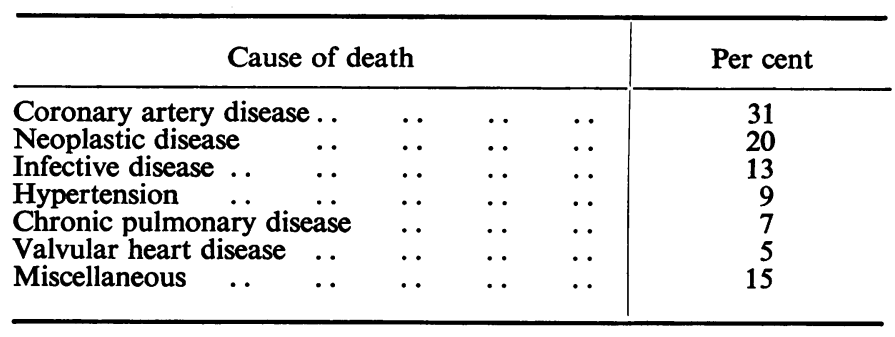


TABLE II

Mean Values and their Standard Errors for Pathology Data

\begin{tabular}{|c|c|c|c|c|c|c|c|c|c|c|}
\hline & & & & & \multicolumn{2}{|c|}{93 men } & \multicolumn{2}{|c|}{63 women } & Men-women & " $t$ " \\
\hline \multicolumn{2}{|c|}{$\begin{array}{l}\text { Right atrial weight (g.) . } \\
\text { Left atrial weight (g.) } \ldots \\
\text { Total atrial weight (g.) } \\
\text { Right atrial volume (ml.) } \\
\text { Left atrial volume (ml.) } \\
\text { Subcutaneous fat (mm.) }\end{array}$} & $\begin{array}{l}\cdots \\
\cdots \\
\cdots \\
\cdots \\
\cdots \\
\cdots \\
\cdots\end{array}$ & $\begin{array}{l}\cdots \\
\ddot{*} \\
\cdots \\
\cdots \\
\cdots \\
\cdots \\
\cdots\end{array}$ & $\begin{array}{l}\cdots \\
\cdots \\
\cdots \\
\cdots \\
\cdots \\
\cdots \\
\cdots\end{array}$ & \multicolumn{2}{|c|}{$\begin{array}{r}31 \cdot 61 \pm 0.966 \\
31 \cdot 75 \pm 0.981 \\
77.46 \pm 2.047 \\
91.03 \pm 2.883 \\
76.14 \pm 2.590 \\
14 \cdot 31 \pm 0.900 \\
67.45 \pm 0.295 \\
69.15 \pm 1.409 \\
410.74 \pm 11.751\end{array}$} & \multicolumn{2}{|c|}{$\begin{array}{r}26 \cdot 62 \pm 0.943 \\
28 \cdot 16 \pm 1.017 \\
67 \cdot 27 \pm 2 \cdot 110 \\
74 \cdot 38 \pm 2 \cdot 883 \\
63 \cdot 49 \pm 3.069 \\
17 \cdot 62 \pm 1 \cdot 541 \\
63 \cdot 40 \pm 0.357 \\
68 \cdot 70 \pm 2 \cdot 016 \\
338 \cdot 46 \pm 12 \cdot 385\end{array}$} & $\begin{array}{r}4.99 \pm 1.35 \\
3.59 \pm 1.37 \\
10.19 \pm 3.03 \\
16.65 \pm 3.83 \\
12.65 \pm 4.02 \\
-3.31 \pm 1.78 \\
4.05 \pm 0.46 \\
0.45 \pm 2.46 \\
72.28 \pm 17.06\end{array}$ & $\begin{array}{l}3 \cdot 70 \\
2 \cdot 62 \\
3 \cdot 36 \\
4 \cdot 35 \\
3 \cdot 15 \\
1 \cdot 86 \\
8 \cdot 80 \\
0 \cdot 18 \\
4 \cdot 24\end{array}$ \\
\hline \multicolumn{6}{|c|}{ Comparison } & \multicolumn{3}{|c|}{ Men } & Women & "t" \\
\hline \multicolumn{5}{|c|}{$\begin{array}{l}\text { Right atrial weight minus left atrial weight } \\
\text { Right atrial volume minus left atrial volume }\end{array}$} & $\ddot{\cdots}$ & \multicolumn{3}{|c|}{$\begin{array}{r}-0 \cdot 14 \pm 1 \cdot 33 \\
14 \cdot 89 \pm 3 \cdot 88\end{array}$} & $\begin{array}{r}-1 \cdot 54 \pm 1.39 \\
10.89 \pm 3.99\end{array}$ & $\begin{array}{l}(1 \cdot 11) \\
(2 \cdot 73)\end{array}$ \\
\hline
\end{tabular}

Note: In addition to the 98 patients of the study proper, atrial magnitudes were determined for an additional 58 routine necropsy subjects (who did not have electrocardiograms) as part of an overlapping study. These latter 58 observations have been included in the above Table. They have not, of course, been used in the estimation of relationships between $\mathbf{P}$ waves and atrial magnitudes, nor in the derivation of equations linking electrocardiographic and necropsy measurements.

TABLE III

Mean Values and their Standard Errors for Electrocardiographic Data

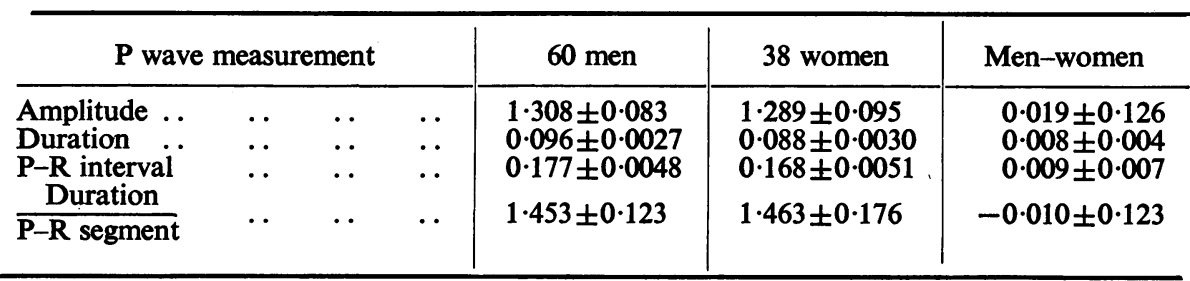

with malignant disease are also considered, it will be seen that very few patients may be considered to have had "normal" hearts.

The frequency distributions of the various quantities approximated to a "normal" distribution, except in the case of quantities measured on a five-point scale (heart fat, atrial fat, and degree of rigor mortis).

The means and their standard errors are listed in Tables II and III, along with sex comparisons. No significant sex differences emerged for the electrocardiographic measurements, except in the case of the $\mathbf{P}$ wave duration where the difference was just significant at the " 5 per cent level".

Four different machines were used in the collection of the $P$ wave data. Differences due to machines were not significant (see Table IV), so that no further allowance was made for the differences.

A preliminary examination was made of some 60 correlations between electrocardiographic data and the atrial measurements. Correlations for women appeared less significant than for men owing to the rather small sample size (38). In view of rather significant sex differences in atrial measurements, it was decided to fit parallel regressions to the two sexes, thus allowing for a common correlational pattern for the two sexes, but leading to separate estimating equations for expected atrial magnitudes. Tests were made for significance of sex differences, significance of over-all regression relationships, and for any departures from "parallelism" between the two sexes. In all 
TABLE IV

VARIATIONS AMONG MACHINES

(98 electrocardiograms)

\begin{tabular}{|c|c|c|c|c|c|c|}
\hline & & \multicolumn{4}{|c|}{ Type of machine } & \multirow{2}{*}{$\begin{array}{l}\text { F-value for } \\
\text { machine } \\
\text { differences* }\end{array}$} \\
\hline & & Heat write & Red ink & Purple ink & Black ink & \\
\hline $\begin{array}{l}\text { Number of times used } \\
\text { Mean amplitude (mm.) } \\
\text { Mean duration (sec.) } \\
\text { Mean P-R interval (sec.) }\end{array}$ & $\begin{array}{l}\cdots \\
\cdots \\
\cdots\end{array}$ & $\begin{array}{l}41 \\
1 \cdot 30 \\
0 \cdot 089 \\
0 \cdot 174\end{array}$ & $\begin{array}{l}44 \\
1 \cdot 37 \\
0.098 \\
0 \cdot 175\end{array}$ & $\begin{array}{l}\quad 8 \\
0 \cdot 81 \\
0 \cdot 088 \\
0 \cdot 173\end{array}$ & $\begin{array}{l}5 \\
1 \cdot 35 \\
0.094 \\
0 \cdot 196\end{array}$ & $\begin{array}{l}1 \cdot 91 \\
1 \cdot 87 \\
0 \cdot 58\end{array}$ \\
\hline
\end{tabular}

* Each F-test has 3 and 92 degrees of freedom. The critical value at the " 5 per cent level " of significance is $\mathrm{F}=2 \cdot 71$ so that differences due to machines are not significant.

TABLE V

Regression Coefficients and Significance Tests for Relationships between Atrial Measurements and ELECTROCARDIOGRAMS

\begin{tabular}{|c|c|c|c|c|c|}
\hline \multirow{2}{*}{$\begin{array}{c}\text { Dependent } \\
\text { variable }\end{array}$} & \multicolumn{3}{|c|}{ Regression coefficient of independent variable } & \multirow[t]{2}{*}{ Constant } & \multirow[t]{2}{*}{$\mathbf{F}$} \\
\hline & $\mathbf{X} 1$ & $\mathbf{X} 2$ & $\mathbf{X} 3$ & & \\
\hline $\mathbf{Y 1}$ & $-0.81(0.72)$ & & $66 \cdot 2(3 \cdot 29)$ & $\begin{array}{l}19.99 \text { (men) } \\
16.27 \text { (women) }\end{array}$ & $5 \cdot 63$ \\
\hline $\mathbf{Y} 2$ & $-2 \cdot 16(1 \cdot 77)$ & & $104 \cdot 4(4 \cdot 74)$ & $\begin{array}{l}15.77 \text { (men) } \\
14.62 \text { (women) }\end{array}$ & $12 \cdot 68$ \\
\hline Y3 & $-3 \cdot 32(1 \cdot 29)$ & & $195 \cdot 2(4 \cdot 30)$ & $\begin{array}{l}45.26 \text { (men) } \\
39.89 \text { (women) }\end{array}$ & $10 \cdot 07$ \\
\hline Y4 & $-1 \cdot 21(0.33)$ & $268(2 \cdot 47)$ & & $\begin{array}{l}76.46 \text { (men) } \\
62.78 \text { (women) }\end{array}$ & $4 \cdot 54$ \\
\hline Y5 & $-9.05(2.65)$ & $299(2 \cdot 89)$ & & $\begin{array}{l}68.22 \text { (men) } \\
62.25 \text { (women) }\end{array}$ & $7 \cdot 22$ \\
\hline
\end{tabular}

Notes: (i) Relationships are of the form $\mathrm{Y} 1=-0 \cdot 81 \mathrm{X} 1+66 \cdot 2 \mathrm{X} 3$, etc.

(ii) Y1, right atrial weight; Y2, left atrial weight; Y3, total atrial weight, Y4, right atrial volume; Y5, left atrial volume. Weights are in grams and volumes in $\mathrm{ml}$.

(iii) X1, $\mathrm{P}$ wave amplitude; $\mathrm{X} 2$, $\mathrm{P}$ wave duration; $\mathrm{X} 3, \mathrm{P}-\mathrm{R}$ interval.

(iv) Values in parentheses are values of the " $t$ " statistic with 95 degrees of freedom.

cases, sex differences in atrial magnitudes were significant, the regressions were significant, but there were no significant departures from parallelism between the linear relationships for the two sexes.

Linear relationships were sought between the various atrial magnitudes on the one hand and $P$ wave amplitude, $\mathbf{P}$ wave duration, and $\mathbf{P}-\mathbf{R}$ interval on the other. $\mathbf{P}$ wave amplitude was included in each such relationship, whether making a statistically significant contribution or not. Each of the other two parameters was included only where it made a significant contribution. In all relationships concerning atrial volumes, the effect of the degree of rigor mortis of the heart was taken into account.

Atrial Weight versus $P$ Wave Amplitude, Duration, and $P-R$ Interval. For both right and left atrial weights and the total atrial weight the $P$ wave duration made no significant contribution so that the relationships link the atrial weights to the $P$ wave amplitude and the $P-R$ interval. The amplitude appeared to be of greater importance for the left atrium than for the right. Indeed its contribution to the determination of the right atrial weight was without statistical significance.

The equations connecting the atrial weights and the two wave parameters are reasonable enough for expressing average trends, but they are of little use for estimating the atrial weights of a single individual from his or her $\mathbf{P}$ wave measurements. The extent of individual variability was such that reasonable estimates could not be made to within 45 or 55 per cent in any individual patient (Table V). 
TABLE VI

Significance Tests for Coefficients of Regression of Atrial Magnitudes on Two Different Wave PARAMETERS

\begin{tabular}{|c|c|c|c|c|c|c|c|}
\hline \multirow{2}{*}{\multicolumn{5}{|c|}{ Atrial measurement }} & \multicolumn{3}{|c|}{ " $t$ " statistic for partial regression coefficient of:- } \\
\hline & & & & & $\begin{array}{c}\mathbf{P} \text { wave duration } \\
-\end{array}$ & \multirow{2}{*}{$\begin{array}{c}\text { P-R interval } \\
3 \cdot 29 \\
4 \cdot 74 \\
4 \cdot 30\end{array}$} & $\frac{\mathbf{P} \text { wave duration }}{\mathbf{P}-\mathbf{R} \text { segment }}$ \\
\hline $\begin{array}{l}\text { Right atrial weight } \\
\text { Left atrial weight } \\
\text { Total atrial weight } \\
\text { Right atrial volume } \\
\text { Left atrial volume }\end{array}$ & $\begin{array}{l}\ldots \\
\cdots \\
\cdots \\
\cdots\end{array}$ & $\begin{array}{l}\ldots \\
\cdots \\
\cdots \\
\cdots\end{array}$ & $\begin{array}{l}\ldots \\
\cdots \\
\cdots \\
\cdots\end{array}$ & $\begin{array}{l}\ldots \\
\cdots \\
\cdots \\
\cdots\end{array}$ & $\begin{array}{l}- \\
\overline{-} \\
2 \cdot 47 \\
2 \cdot 89\end{array}$ & & $\begin{array}{l}2 \cdot 12 \\
1 \cdot 93 \\
1 \cdot 98 \\
1 \cdot 40 \\
1 \cdot 11\end{array}$ \\
\hline
\end{tabular}

Notes : (i) In all cases the second independent variable was the $P$ wave amplitude.

(ii) Each value of " $t$ " has 95 degrees of freedom.

(iii) Only the first value of " $t$ " in the last column is significant at the 5 per cent level.

Atrial Volumes versus $P$ Wave Amplitude, Duration, and $P-R$ Interval. On this occasion the P-R interval made no significant contribution so that the relationship that remained was that between the atrial volumes on the one hand and the amplitude and the $P$ wave duration on the other. The atrial volumes were greater for small amplitudes and larger $\mathbf{P}$ wave durations. The amplitude appeared to be of greater importance for the left atrium than for the right, its contribution to the determination of the right atrial volume being of little significance. Again the estimating equation was unsuitable for use in the case of a single individual though satisfactory for expressing a general average trend (Table V).

Atrial Magnitudes versus $P$ Wave Amplitude and Quantity $P$ Wave Duration/P-R Segment. For both right and left atrial weights as well as for total atrial weight the dependence on the ratio of the wave duration to the $P-R$ segment was less than the dependence on the $P-R$ interval. Correlation between the weight and this ratio was negative for both right and left atria. Statistical significance was relatively low.

For the atrial volumes, the dependence on the above ratio was less than the dependence on the $P$ wave duration. Correlations on this occasion were both positive, but statistical significance was not achieved.

Hence, replacement of the P-R interval by this ratio resulted in a loss of information about atrial weights, while replacement of the $P$ wave duration by this ratio resulted in a loss of information about atrial volumes.

Relevant data are given in Table VI.

$P$ Wave and Heart Fat. An examination was made of the relationship of the $P$ wave parameters to the three fat determinations (epicardial fat, right atrial fat, and left atrial fat). The only significant (partial) regressions that emerged were a negative regression of amplitude on right atrial fat $(p<0.05)$ and a negative regression of amplitude on epicardial fat $(p<0.05)$. The amount of fat appeared unrelated to either the $\mathbf{P}$ wave duration or the $\mathbf{P}-\mathbf{R}$ interval.

Summary of Results. (1) The analysis of electrocardiographic $P$ wave records of 60 men and 38 women showed no significant sex differences with respect to $P$ wave amplitude, $P$ wave duration, or P-R interval.

(2) $\mathbf{P}$ wave amplitude furnished little information about the right atrial weight or the right atrial volume. It did, however, provide information about left atrial magnitudes (especially the left atrial volume). Flatter $\mathbf{P}$ waves were associated with greater left atrial magnitudes.

(3) $P$ wave duration showed no correlation with atrial weights, but did display significant positive correlation with both atrial volumes.

(4) P-R interval showed no correlation with atrial volumes but did display significant positive correlation with both atrial weights. 
(5) The substitution of the quantity $\frac{P \text { wave duration }}{P-R \text { segment }}$ for the $P-R$ interval or for the $P$ wave duration in the foregoing analyses resulted each time in a loss of information about atrial magnitudes.

(6) Substantial individual variability in atrial measurements makes it impracticable (for patients of this type) to use the equations connecting atrial magnitudes with $\mathrm{P}$ wave data for the purpose of estimating an individual's atrial magnitudes from his $\mathbf{P}$ wave. However, these equations do provide substantial information about the whole class of patients from whom the sample was drawn.

(7) Epicardial fat and right atrial fat were associated with a diminished $\mathbf{P}$ wave amplitude. The other $P$ wave parameters appeared to be unaffected by the epicardial or atrial fats.

\section{DisCUSSION}

The method used for measurement of atrial volumes is open to criticism, since it is difficult to judge when the atrium is fully expanded without overstretching, and whether herniation has occurred through the atrio-ventricular ring. Volumes measured in this way thus tend to be falsely high, though the effect of rigor mortis tends to act in the opposite direction. Measurements of atrial volume have been attempted on the living subject by angiocardiography (Macruz et al., 1958; Soloff and Zatuchni, 1958), but it is not easy accurately to derive volume measurements from measurements in one, or even several planes, and variations during the cardiac cycle must introduce errors.

Mass should be the best measure of muscle bulk or hypertrophy, but can only be measured in the necropsy room. The amount of epicardial fat, which varies greatly from patient to patient and has no electrical activity, introduces an error. Reiner et al. (1959) found it impossible to remove all of it by sharp dissection, which is not surprising when it is remembered that fat is infiltrated between the muscle fibres. We chose, therefore, not to attempt to remove the epicardial fat, but to take it into consideration in assessing our results.

One of the major difficulties of work involving the electrocardiographic $\mathbf{P}$ wave is the small size of the measurements. Because of this it is difficult on the routine electrocardiogram to recognize variations in voltage of less than $0.25 \mathrm{~mm}$., which in many cases represent a change in amplitude of the order of 25 per cent. Any small errors in measurements of this magnitude assume great relative importance.

Factors other than those acting through atrial magnitudes which might influence the size and shape of $\mathbf{P}$ waves include position of the heart, respiratory variations, heart rate, thickness of the chest wall, the effect of drugs and toxins, and variations in electrocardiographic technique.

$P$ Wave Duration. Either the initial or the final electrical activity, or both, may be missing from any one lead, depending on the direction of the vector at the time in relation to that lead. The most complete representation of such electrical activity is seen in the lead showing the widest $P$ waves in the tracing. Diphasic waves are usually of long duration, since that particular electrode has recorded a deflection as the vector moved towards, as well as away, and is often the one best oriented to record the total duration of atrial electrical activity. When we related the maximal $P$ wave duration of the 12-lead electrocardiogram to atrial measurements in this study, we found a significant positive correlation with right and left atrial volumes.

Caceres and Kesler (1959) studied the tracings of 50 normal men and found an average maximal $P$ wave duration of $0.13 \mathrm{sec}$. They concluded that $P$ waves less than $0.12 \mathrm{sec}$. in duration were not representative of atrial activity. We found the average maximal $P$ wave duration for 60 men was $0.096 \mathrm{sec}$. and for 38 women $0.088 \mathrm{sec}$. (sex differences not significant). Ashman and Hull (1941) state the range for maximal $P$ wave duration (widest $P$ wave of 3 standard leads) for 100 normal subjects to be $0.06-0.11 \mathrm{sec}$. (average $0.08 \mathrm{sec}$.) and that the duration in men is slightly greater than in women.

$P$ Wave Amplitude. The tallest $\mathrm{P}$ wave should occur in that lead best oriented towards the maximal spread of activity, while the positivity or negativity of the deflection depends on direction of spread of depolarization only. 
It might be expected that $\mathbf{P}$ wave amplitude would correlate in a positive way with atrial mass in a study such as this one, but this was not the case. Instead it correlated very strongly in a negative way with left atrial volume and less strongly, though still significantly, in a negative way with left atrial mass. There was no significant correlation with right atrial magnitudes.

Thus from our figures, patients with large left atrial magnitudes tend to have broader flatter $\mathbf{P}$ waves.

These results are readily explained if the contribution to the $\mathbf{P}$ wave by each atrium is considered independently, with particular reference to its timing and the degree of summation or superimposition. Since the right atrium begins to depolarize before the left, prolongation of right atrial depolarization (as might occur with hypertrophy or dilatation) does not prevent summation. Prolongation of left atrial depolarization, however, means that its major contribution to the $P$ wave occurs after right atrial depolarization has been completed, no summation occurs, and a low voltage, wide $\mathbf{P}$ wave results.

$P-R$ Interval. The duration of the P-R interval depends on the distance travelled by the impulse, on metabolic conditions within the muscle fibre, and on any delay in conduction within the atrioventricular node.

The shortest path taken by impulses from the sino-atrial node (upper end of crista terminalis in wall of right atrium) to the atrio-ventricular node (septal wall of right atrium) lies for the most part in septal tissue, and changes in volume of right or left atria or both would not be expected to affect the length of this path to any great extent. In this study the P-R interval showed no correlation with atrial volumes, but was significantly positively correlated with both atrial weights. A role for atrial fat in this correlation would be mere speculation.

Macruz et al. (1958) proposed a new method for diagnosis of atrial enlargement based on the relationship between duration of $P$ wave, $P-R$ interval, and $P-R$ segment, the last being the interval between the end of the $P$ wave and the beginning of the QRS. They deduced that right atrial enlargement would prolong the $P-R$ interval and alter the configuration of the $P$ wave but would not usually affect the $P$ wave duration. Left atrial enlargement should be associated with a normal P-R interval, but increased $\mathbf{P}$ duration. Combined atrial hypertrophy posed a problem, however, by resulting in a normal ratio.

Substitutions of the quantity $\frac{P \text { wave duration }}{P-R \text { segment }}$ for $P-R$ interval in our study resulted each time in a loss of information about atrial magnitudes.

\section{SUMMARY}

Necropsy on the hearts of 98 patients included measurement of right and left atrial weights and volumes. Electrocardiograms were available for these patients, and maximal $P$ wave amplitude and duration, and maximal P-R interval were measured in each case.

The dependence of these various components of the $P$ wave upon atrial size was investigated statistically, and a means was sought whereby the size of the atria might in a particular case be estimated from the electrocardiogram. Significant correlations were found between certain atrial parameters and $\mathbf{P}$ wave measurements. For example, $\mathbf{P}$ wave duration showed significant positive correlation with both atrial volumes, and $\mathrm{P}-\mathrm{R}$ interval was positively correlated with both atrial weights. $\mathbf{P}$ wave amplitude was negatively correlated with left atrial volume, and also to a lesser degree negatively correlated with left atrial weight.

Individual variability in atrial measurements was such, however, that the equations connecting atrial magnitudes with $\mathrm{P}$ wave data did not provide a means of prediction of an individual's atrial magnitudes from his $P$ wave. These equations do provide substantial information about the whole class of patients from whom the sample was drawn. 
We would like to thank Dr. O. W. Powell, Superintendent, Princess Alexandra Hospital, Brisbane, for permission to perform this study and Dr. J. Little and the Staff of the Morbid Anatomy Department for their co-operation. We are indebted to Dr. D. S. Hooper of the University of Queensland Medical School for much of the computational work.

\section{REFERENCES}

Ashman, R., and Hull, E. (1941). Essentials of Electrocardiography, 2nd ed. Macmillan, New York.

Berliner, K., and Master, A. M. (1938). Mitral stenosis: A correlation of electrocardiographic and pathologic observations. Arch. intern. Med., 61, 39.

Caceres, C. A., and Kelser, G. A., Jr. (1959). Duration of the normal P wave. Amer. J. Cardiol., 3, 449.

Dines, D. E., and Parkin, T. W. (1959). Some observations on P-wave morphology in precordial lead V1 in patients with elevated left atrial pressures and left atrial enlargement. Proc. Mayo Clin., 34, 401.

Katz, L. N. (1946). Electrocardiography, 2nd ed. Lea and Febiger, Philadelphia.

Leatham, A. (1950). The chest lead electrocardiogram in health. Brit. med. J., $12,213$.

Macruz, R., Perloff, J. K., and Case, R. B. (1958). A method for the electrocardiographic recognition of atrial enlargement. Circulation, 17, 882.

Reiner, L., Mazzoleni, A., Rodriguez, F. L., and Freudenthal, R. R. (1959). The weight of the human heart: I. "Normal" cases. A.M.A. Arch. Path., 68, 58.

Soloff, L. A., and Zatuchni, J. (1958). Relationship of the P wave to left atrial volume in rheumatic heart disease with mitral stenosis. Amer. J. med. Sci., 235, 290.

White, P. D. (1951). Heart Disease, 4th ed. Macmillan, New York. 